\title{
BM] Global Health Out of control: profit-seeking behaviour, unnecessary medical procedures and rising costs of private medical care in South Africa
}

\author{
Shakira Choonara, John Eyles
}

To cite: Choonara S, Eyles J. Out of control: profit-seeking behaviour, unnecessary medical procedures and rising costs of private medical care in South Africa. BMJ Global Health 2016;1: e000013. doi:10.1136/ bmjgh-2015-000013

Received 20 November 2015 Revised 19 April 2016 Accepted 20 April 2016
CrossMark

Faculty of Health Sciences, Centre for Health Policy and MRC Research Unit, School of Public Health, University of the Witwatersrand, Johannesburg, South Africa

\section{Correspondence to} Shakira Choonara; Shakira. Choonara@wits.ac.za

\section{ABSTRACT}

The World Health Assembly passed a resolution on the importance of engaging with the private health sector. However, the reality is that universal health coverage aspirations are particularly challenging when there is a significant private health sector. This sector in South Africa suffers from rapidly increasing costs, inflation and volume of services (unnecessary medical tests or treatments). This commentary draws on the international literature, particularly the Japanese model of healthcare, to illustrate that it is necessary and possible to curtail costs and volume in the private sector in South Africa, and possibly in other low-income and middle-income settings.

\section{START OF COMIMENTARY}

In virtually every country, healthcare professionals have a high social standing. They are trusted to perform their duties in the best interests of their patients, and are rewarded with high prestige and usually high incomes, generated by salary or fees-for-service. These professionals, especially physicians in the private sector, are seen as vital in the provision of healthcare as low-income and middle-income countries move towards universal health coverage. The World Health Assembly passed a resolution on the importance of engaging with the private health sector. ${ }^{1}$ However, the reality is that universal health coverage aspirations are particularly challenging when there is a significant private health sector. The reality is that the private sectors are geared towards profit instead of aiming at social justice and the provision of healthcare to all citizens, catering overwhelmingly to patients who are able to afford private health services. Internationally, in China and the USA, the marked impact of privatisation of health services resulted in increased healthcare costs and poor health outcomes, providing the rationale for the call for affordable healthcare in such countries. ${ }^{2-4}$ The case is no different in South Africa, where $8.5 \%$ of the gross domestic product is spent on healthcare, with over $50 \%$ attributable to private healthcare spending, which only covers $17 \%$ of the population thereby skewing financial and human resources in health to serve a small minority of the population. ${ }^{5}$ It is argued that financing of healthcare in South Africa is inequitable and unaffordable for the poor, who are still largely marginalised, as well as for those at risk of catastrophic health expenditure when medical schemes fail to cover certain medical conditions. ${ }^{6}$ Moreover, the middleclass are subject to rapidly increasing medical aid scheme contributions and high out-of-pocket payments when benefits run out, rendering the private health sector unsustainable. This largely for-profit sector is shaped by insurance companies, medical schemes and professionals' profit motives. The sector itself suffers from rapidly increasing costs, inflation and volume of services (unnecessary medical tests or treatments). The South African government has tasked the country's Competition Commission to investigate the sector; a delayed report is expected in December 2016. This commentary focuses on these challenges, and proposes how these costs can and should be curtailed.

\section{VOLUME CONTROL IS NECESSARY TO CURTAIL COSTS}

A fee-for-service model is currently used in South Africa's private healthcare sector, to reimburse professionals for services or procedures carried out, thereby creating an incentivised environment to carry out unnecessary medical procedures or tests, in other words, a high volume of services. ${ }^{6}$ The WHO recently reported that, in higher income 
countries, caesarean sections are often performed unnecessarily, and linked to negative health outcomes for mothers and their infants. ${ }^{7}$ Aside from preventing birth complications and avoiding legal action, higher profits comprise one of the factors linked to the increase in caesarean sections, even in cases where women are healthy and prefer to have natural birth. In Brazil, there have been instances where doctors request bribes if a woman does not want to have a caesarean birth. Fees vary from doctor to doctor in Namibia, yet higher profit margins are associated with carrying out C-sections. ${ }^{8}$ In South Africa, gynaecologists have to pay high insurance premiums and prefer to carry out C-sections in order to pay these premiums, and there are even some reports of C-sections being carried out when they are not needed. ${ }^{10}$ Existing research in South Africa indicates that $80 \%$ of women interviewed preferred natural birth; some were 'coerced or bullied' into surgical birth. ${ }^{10}$ Volume control affects even developed countries. In the USA, there has been some debate around using mammograms to screen false positive women, with a previous study reporting that it incurred a mean cost of US $\$ 527 .^{11}$ Another study from the USA draws attention to unnecessary colonoscopies-close to $40 \%$ of patients had colonoscopies despite being too old to benefit from these, and underwent unnecessary risk such as of bowel perforation. ${ }^{12}$ These are just some examples of the drive for higher incentives and profits that is contributing to an unethically high volume of services/unnecessary surgical procedures, infringement on patient rights and spiralling costs in the private sector.

\section{THE PRIVATE SECTOR MUST BE REGULATED AND EXTRA BILLING SHOULD BE BANNED}

Costs are often determined by a fee schedule, which sets the price for all procedures, drugs, devices and so on. The fee schedule determines how much the physician and associated services charge medical schemes and insurance companies, and also reckons the out-of-pocket expenses of individual patients. Under South Africa's Medical Scheme Act of 1998, the Council for Medical Schemes is the regulator for medical schemes and not the regulator for private healthcare providers. In its 2014/2015 annual report, even the Council for Medical Schemes is cognisant of the negative implications of an unregulated private health sector. The problem arises when services are charged at a rate that is over and above the reference price. This is known as extra billing and can cost the scheme or the patient a great deal. According to the Health Professions Council of South Africa, a lack of regulation of tariffs has contributed to high costs, where private doctors and dentists charge as much as five times the medical aid rate. ${ }^{13}$ In South Africa, the government has been unable to attract a substantial amount of professionals to its universal health coverage initiative, as private professionals earn up to six times more than their public counterparts. ${ }^{14}$ In fact, price in South Africa is proprietary-a trade secret that lacks transparency and consistency. It is argued that there have been substantial cost increases over the entire recorded history of the South African private healthcare market-specialist cost increases in an unregulated market were found to be $183 \%$ in 2001 and are still continuing to rise. ${ }^{15}$ Moreover, cost increases have been met with declining medical aid benefits thereby placing strain on even those who can afford to pay for private healthcare. ${ }^{15}$ These marked differences point to the need to regulate the private sector, and to then ensure that excess costs are banned and regulated, to curb the costs of private healthcare. Thus far, the South African government has indicated that this will be the case moving forward, however, there is no clear indication in current policy documents, for example, no mention in the country's 'White Paper on National Health Insurance' on how and when this will be accomplished, and minimal focus has been placed on extra billing (the excess amount above regulated rates that physicians can charge).

\section{ONE POSSIBLE MODEL TO CONTAIN HEALTHCARE COSTS}

The Japanese model also makes use of a fee-for-service model, however, unlike South Africa, it has been able to effectively contain costs and volume in the private health sector. Japan's cost containment is attributed to having a nationally uniform fee schedule, audits of medical records, state intervention when drug prices are too high and reimbursement prices being lowered if there is an increase in volume of services, for example, the tariff for MRI was lowered by $30 \%$ when there was an increase in volume in 2002. ${ }^{16}$ In Japan, the ban on extra billing is strongly advocated. The aim of this ban is to prevent the formation of a 'two-tiered healthcare system'. A two-tiered system means that there is a basic healthcare system financed by the government, providing medically necessary but quite basic healthcare services. A secondary tier of care exists for those with access to more funds who can purchase additional healthcare that is not covered by the publicly financed system or that permits better quality or faster access. The ban is meant to prevent inequities among the Japanese people in accessing non-covered treatment. Furthermore, the purpose of the regulation is to ensure patient safety and to prevent fraud-related to non-covered treatments that are not supervised by the government. There are thus solidarity arguments for preventing extra billing and the political role of government in shaping regulation, including oversight of the fee schedule, is central.

Together, the high costs and volume of services points to the inefficient use of financial resources in South Africa. As the country moves towards implementing universal health coverage, it needs to ensure adequate financing and risk pooling, and financial regulation of the healthcare system needs to be tightened. The Health Professions Council of South Africa is itself marked by 
irregular and corrupt expenditure, and is considered to be a dysfunctional body that is able to regulate neither prices nor professionals effectively. This body should be strengthened, its role is critical in curbing unethical behaviour linked to high costs and volume. The Council for Medical schemes also has a crucial role to play in this. Extra billing should be disallowed and a micromanaged transparent fee schedule enacted between government and private providers is urgently required. Such political involvement is also necessary for controlling the volume of services delivered.

Twitter Follow Shakira Choonara at @ChoonaraShakira

Handling Editor Seye Abimbola

Acknowledgements Financial assistance towards this research is hereby acknowledged; opinions expressed and conclusions arrived at are those of the authors.

Contributors SC completed the first draft of the submitted commentary with input and guidance from JE.

Funding SC and JE are funded by the National Research Foundation South Africa: National Research Foundation Freestanding Doctoral; South African Research Chairs Initiative).

Competing interests None declared.

Provenance and peer review Not commissioned; externally peer reviewed.

Data sharing statement Only clips from newspaper articles have been used in the commentary, these have been referenced accordingly.

Open Access This is an Open Access article distributed in accordance with the Creative Commons Attribution Non Commercial (CC BY-NC 4.0) license, which permits others to distribute, remix, adapt, build upon this work noncommercially, and license their derivative works on different terms, provided the original work is properly cited and the use is non-commercial. See: http:// creativecommons.org/licenses/by-nc/4.0/

\section{REFERENCES}

1. Forsberg BC, Montagu D, Sundewall J. Moving towards in-depth knowledge on the private health sector in low- and middle-income countries. Health Policy Plan 2011;26(Suppl 1):i1-3.

2. Blumenthal D, Hsiao W. Privatization and its discontents-the evolving Chinese health care system. $N$ Engl J Med 2005;353:1165-70.

3. Barnard E. The Politics of Canada's Health Care System. New Politics, 1992;3:4.

4. Wolfe B. Changing the US Healthcare System: How Difficult Would It Be? http://www.irp.wisc.edu/publications/focus/pdfs/foc142e.pdf (accessed 2 Nov 2015).

5. Adão V. 2015 health care outlook South Africa. 2014 (cited 2015 02/ 11). https://www2.deloitte.com/content/dam/Deloitte/global/ Documents/Life-Sciences-Health-Care/gx-Ishc-2015-health-careoutlook-south-africa.pdf

6. SANDoH. National Health Insurance of South Africa: moving towards universal health coverage. South African National Department of Health, 2015.

7. WHO. Caesarean sections should only be performed when medically necessary. 2015 (cited 2015 02/11). http://www.who.int/ mediacentre/news/releases/2015/caesarean-sections/en/

8. Filipovic J. Inside a war on natural birth: c-sections as status symbol and 'choice' as a myth. The Guardian 2014.

9. allafrica. Namibia: Private Hospitals Over-Perform C-Sections. 2015. http://allafrica.com/stories/201507170479.html

10. Wort T. Are private hospitals pushing pregnant women to have C-Sections? 2015 (cited 2015 11/04). http://ewn.co.za/2015/02/18/ Are-private-hospitals-pushing-pregnant-women-to-have-C-Sections

11. Chubak J, Boudreau DM, Fishman PA, et al. Cost of breast-related care in the year following false positive screening mammograms. Med Care 2010;48:815-20.

12. Pittman G. Some older adults get unnecessary colonoscopies. Reuters 2013.

13. Malan M. Health professionals are finding the state's planned guidelines for fees a bitter pill to swallow. Mail and Guardian 2013.

14. Ashmore J. 'Going private': a qualitative comparison of medical specialists' job satisfaction in the public and private sectors of South Africa. Hum Resour Health 2013;11:1.

15. Van den Heever A. Administered prices: a report for National Treasury. South Africa, 2000.

16. Hashimoto H, Ikegami N, Shibuya K, et al. Cost containment and quality of care in Japan: is there a trade-off? Lancet 2011;378:1174-82. 